EXTENDED REPORT

\title{
Urinary tract infections and lupus erythematosus
}

\section{Hidalgo-Tenorio, J Jiménez-Alonso, J de Dios Luna, M Tallada, A Martínez-Brocal, J Mario Sabio, "Virgen de las Nieves Lupus Research Group"}

Ann Rheum Dis 2004;63:431-437. doi: 10.1136/ard.2003.006346

See end of article for authors' affiliations

.....................

Correspondence to: Dr C Hidalgo-Tenorio, 9th floor, Hospital Universitario "Virgen de las Nieves", Avda Fuerzas Armadas No 2, 18014, Granada, Spain; chidalgo72@hotmail.com

Accepted 14 July 2003
Background: Infections are one of the main causes of morbidity and mortality in patients with systemic lupus erythematosus.

Objective: To analyse urinary tract infection (UTI) risk factors in lupus patients; the influence of these factors on disease activity, organ damage, and disease development; the type and prevalence of UTI; and the micro-organisms involved.

Method: 86 control subjects and 81 lupus patients were studied prospectively over a 12 month period and examined on five occasions. Epidemiological data and information on urinary symptoms, disease activity (SLEDAI), and organ damage (SLICC/ACR) data were collected. Autoantibodies, complement levels, urine culture, and antibiogram were determined; urological studies were also carried out. SPPS 10.0 and STATA 6.0. were used for statistical analysis.

Results: The prevalence of UTI in lupus patients was 36\%. Lupus influences the onset of UTI $(p=0.001)$, regardless of other variables. UTI risk factors in lupus patients were age $(p=0.002)$, previous cases of UTI $(p=0.0001)$, antinuclear antibodies (ANA) $>1 / 80 \mathrm{IU} / \mathrm{ml}(p=0.022)$, thrombocytopenia $(p=0.02)$, and admission to hospital due to UTI $(p=0.002)$. Leucopenia $(p=0.09)$ and the weekly administration of methotrexate $(p=0.06)$ had a bearing on the onset of UTI; disease development $(p=0.99)$, lupus activity $(p=0.32)$, and organ damage $(p=0.36)$ do not. The uropathogen most frequently isolated was $E$ coli (60\%).

Conclusions: Lupus patients are likely to have UTI, usually manifesting in the lower tract. They are community acquired, basically caused by $E$ coli, and favoured by age, previous UTI, admissions to hospital due to UTI, thrombopenia, ANA, leucopenia, and methotrexate treatments.
$\mathrm{L}$ upus erythematosus is a disease with many clinical manifestations, from a rash to multiorgan dysfunction. -From 1950 onwards, a gradual increase in the survival rate of people with this disease has been seen, which, among other factors, has been due to the greater control of lupus related complications, infections included. ${ }^{1}$ The incidence of infections in patients with systemic lupus erythematosus (SLE) ranges between 50 and 150 episodes in 100 patients a year. Some authors have found that this is the first cause of death in lupus patients ${ }^{2-6}$; others that it is the first ${ }^{5}$ or second cause of admission to hospital. ${ }^{7}$ The susceptibility of lupus patients to infections has been mainly attributed to lupus activity, to the alteration of cellular and humoral immunity, to corticoid treatment, ${ }^{8-11}$ and functional asplenia. ${ }^{12}$ For most authors, urinary tract infection (UTI) is the first $t^{13}$ or second cause of infection-followed by respiratory tract infectionin these patients. ${ }^{14}{ }^{15}$ The micro-organisms most commonly affected in this type of infection are those frequently acquired in the community $(80-90 \%)$, for the most part $E$ coli. ${ }^{14-17}$

Up to the present, most research dealing with infections in lupus patients has been transversal. No prospective, long term studies have been carried out to analyse thoroughly both the different risk factors that may have an effect on the onset of UTI in lupus patients, and their probable influence on the development and prognosis of the disease. The objectives of this study were to determine the incidence and type of UTI in our cohort of lupus patients; to discover the infectious agents involved and their antibiotic resistant pattern; and to identify the factors that might favour the onset of UTI, as well as their probable effect on disease activity, disease development, and organ damage.

\section{PATIENTS AND METHODS}

\section{Patients}

The study started in July 1998 and finished in December 2000. Patients were studied during one year after having given their written informed consent. Initially, 84 patients with SLE and cutaneous lupus (CL) were included in the study; in the end, however, three of them were excluded because they did not complete the follow up. They all came from the Systemic Autoimmune Disease Unit, Department of Internal Medicine, "Virgen de las Nieves" University Hospital, Granada, Spain. Seventy of the 81 patients who had been finally selected had SLE, and fulfilled four or more of the American College of Rheumatism criteria ${ }^{18}$; the other 11 had CL, which was diagnosed by observing clinical and anatomopathological data. The study also included a control group made up of 92 subjects who were healthy or had general complaints unrelated to lupus, urinary pathology, or diabetes. All of them were taken from the researcher's milieu and had a distribution of sex and age similar to that of the lupus group. Eventually, six of the 92 healthy subjects had to be excluded because they did not complete the study.

\footnotetext{
Abbreviations: aCL, anticardiolipin antibodies; $\mathrm{ANA}$, antinuclear antibodies; Cl, confidence interval; $\mathrm{CL}$, cutaneous lupus; GEE, generalised estimation equation; LA, lupus anticoagulant; $O R$, odds ratio; SLE, systemic lupus eythematosus; SLEDAl, Systemic Lupus Erythematosus Disease Activity Index; SLICC/ACR, Systemic Lupus International Collaborating Clinics/American College of Rheumatism; ufc, ??; UTI, urinary tract infection
} 


\section{Definitions}

Sexual activity was considered a UTI risk factor when the patient had sexual intercourse four times a month. ${ }^{19}$ The diagnosis of chronic constipation was based upon Rome's criteria. $^{20}$ Low urine frequency was considered when the subject urinated four or fewer times a day. ${ }^{21}$ Complicated UTI was considered in cases of repeated UTIs, with signs and symptoms in the upper tract, and/or an anatomical or functional alteration in the urinary tract, immunological deficits, pregnancy, and antibiotic resistant uropathogens. ${ }^{21}$ Uncomplicated UTI was diagnosed in cases of positive urine culture ( $\geqslant 10^{2}$ colony forming units/ml urine), urinary symptomatology, and lack of UTI predisposing factors (excluding UTI in sexually active women). ${ }^{21}$ For the diagnosis of asymptomatic bacteriuria, two consecutive $>10^{5} \mathrm{cfu} / \mathrm{ml}$ urine cultures had to be recorded. ${ }^{22}$ The total number of UTI episodes throughout the one year follow up was calculated by adding up the number of complicated and uncomplicated UTI episodes, and asymptomatic bacteriuria episodes. Repeated UTI was considered to occur when the subject had had three or more episodes over the course of one year. The diagnosis of detrusor instability (or hyperactive bladder) was confirmed when the detrusor showed involuntary contractions, with variable frequency and intensity higher than $15 \mathrm{~cm}$ of $\mathrm{H}_{2} \mathrm{O}$, which were not inhibited during vesical filling and were frequently related to urinary urgency. ${ }^{23}$ Hypoactive bladder was diagnosed when there was a large filling volume, delay in urinary voiding, or low detrusor pressure with low urinary flow. ${ }^{24}$ Female urinary incontinence was identified by taking into account clinical criteria and urodynamic studies. ${ }^{25}$ The diagnosis of lower urinary tract obstruction (prostatism) in men was determined in accordance with clinical manifestations, rectum examination, isolated flowmetry, and vesicoprostatic echography. The total accumulated drug dosage was calculated by multiplying the daily dose given by the total number of treatment days.

\section{Protocol}

During the one year follow up, patients were examined on five occasions: at the beginning of the study, and in the lst, 3rd, 6th, and 12th months.

\section{Lupus patients}

On the first visit the following variables were recorded on a database (Microsoft Access 98): age, sex, duration of the disease, lupus type (CL, SLE), previous cases of UTI, number of admissions to hospital due to UTI, UTI predisposing risk factors (Sjögren's syndrome included), current treatment for lupus, and total accumulated dosage of danazol, prednisone, antimalarial drugs (chloroquine and hydroxychloroquine), and immunosuppressive agents (azathioprine, methotrexate, cyclophosphamide, cyclosporin A, and mycophenolate mofetil). On the next occasions, patients were asked about their urinary habits, and were required to record their urinary frequency, diuresis, and approximate daily volume of liquid drunk in the week before the visit. They were then asked about their potential urinary incontinence, the severity of which was measured according to the following scale: $0=$ no loss of urine; $1=$ light loss of urine; 2 = mild loss of urine; and $3=$ loss of urine with minimal activity, or gravitational incontinence. ${ }^{25}$ Lupus disease activity was established in accordance with the Systemic Lupus Erythematosus Disease Activity Index (SLEDAI) score ${ }^{26}$; and organic damage, according to the Systemic Lupus International Collaborating Clinics/American College of Rheumatism (SLICC/ACR). ${ }^{27} \mathrm{~A}$ full physical examination of the patients was also carried out; they were asked questions about clinical data in the 20 days before the visit. This questionnaire included the following items: arthralgias, arthritis, myalgias, photosensitivity, butterfly rashes, oral aphthas, asthenia, costal pain, dyspnoea, temperature, anorexia, loss of weight, convulsions, diarrhoea, vomiting, abdominal pain, ocular symptoms, pollakiuria, dysuria, suprapubic pain, tenesmus, changes in the colour and smell of urine, foaming urine, pain in renal fossa, and shivering.

The laboratory assays carried out on the five visits included the following: standard biochemical test; haemogram; erythrocyte sedimentation rate; $\mathrm{C}$ reactive protein; urinary sediment; proteinuria in 24 hour urine; nDNA, and complements C3 and C4; urine culture (on cystine lysine electrolyte deficient medium); and antibiogram, through a quantitative method of minimal inhibitory concentration obtained by using WIDER I Difco panels (Dade Microsan Inc, West Sacramento, CA, USA) and following the current antibiotic susceptibility criteria for the uropathogens suggested by the National Committee for Clinical Laboratory Standards. ${ }^{28}$ An immunological study was also carried out on the first visit which included: antinuclear antibodies (ANA), Sm, Ro/SSA, $\mathrm{La} / \mathrm{SSB}$, and antiribosomal P0. Furthermore, anticardiolipin antibodies (aCL), IgM and IgG, and lupus anticoagulant (LA) were tested on the first and third visits. Patients with UTIs were given antibiotics in accordance with the antibiogram and, after treatment, another urine culture was carried out. Patients with asymptomatic bacteriuria were given antibiotic prophylactic treatment under the following circumstances: pregnancy, immunosuppression (leucopenia, hypocomplementaemia, and immunosuppressant treatment), bacteriuria by Proteus, and persistent bacteriuria 3-5 days after an intravesical catheter. ${ }^{28}$ When the urine culture remained positive on three consecutive visits despite the antibiotic treatment, the patient was treated with antibiotic prophylaxis for 6 months, with the urine culture being controlled in the first, third, and sixth months. Postcoital prophylaxis was given when we suspected UTI was due to sexual activity, whereas nocturnal prophylaxis was used in the other cases. Finally, a genitourinary echography was carried out in order to rule out structural alterations (either congenital or acquired), as well as a urodynamic study, to rule out functional alterations during urinary voiding. This urodynamic study included isolated flowmetry as a screening test, followed by cystometry and a pressure flow test in accordance with the following protocol: when the flowmetry showed normal parameters and the patient did not have urogenital manifestations (that is, stress incontinence, prostatism, or micturitional syndrome), the urogenital study was stopped. On the contrary, the study was continued in the three following situations: (a) when flowmetry was not normal regardless of the patient's clinical manifestations; $(b)$ when, despite flowmetry being normal, the patient had urogenital manifestations; and (c) when, after repeating a doubtful flowmetry, this continued to be doubtful or abnormal.

\section{Control group}

The control subjects were asked about previous cases of UTI, UTI risk factors, clinical manifestations, urinary habits, and incontinence in the same way and during the same period of time as the lupus patients. They were also subjected to the same supplementary tests except for the immunological study.

\section{Statistical analysis}

A descriptive analysis of variables (that is, median score and standard deviation) was performed for both the lupus and the control groups. Dichotomic variables were expressed in percentages. Mann-Whitney $U$ and $\chi^{2}$ tests were used as appropriate. The level of significance was $p<0.05$. To determine the factors that influence the onset of UTI on the five visits, we used the generalised estimation equation 
model (model GEE), with a non-structured correlation matrix for categorical data, and the binomial distribution and the "logit" as a natural link. Thus, the "natural" measure for the effect is the "cross-product ratio". The appropriate goodness of fit test was used, which did not show significant results in any of the cases. Firstly, a comparative study was also carried out between the lupus and the control group; and, later on, within the lupus group itself. A three stage procedure was followed, which resulted in the adjustment of a multivariate model: (a) a bivariate analysis (model 0 ) was performed for each item in order to measure their individual effect on the response variable; $(b)$ we took those significant variables from the previous analysis or those that were to be controlled but were not significant, and we produced a joint multivariate model (model I) in order to measure the net effects of such variables; (c) by eliminating the variables of model I that did not provide any information on the response variable and did not cause significant changes in the model coefficients, we produced a definitive model (model II). This last model was the one presented for the final study. This procedure aimed at avoiding having an excessive number of variables (parsimonious model), without eliminating any that might provide information on the response variable, directly or indirectly. The following statistical programs were used: SPSS 10.0, in the first part of the study; and STATA 6.0, in the different comparisons.

\section{RESULTS}

\section{Descriptive analysis}

Demographic data, UTI prevalence, type and risk factors in the lupus and control groups

Seventy three of $81(90 \%)$ lupus patients were women and 8 (10\%) men. The average age was 41.4 (SD 11.9) years (range 18-69). The average disease duration was 7.9 (SD 5.8) years (range 0-28). The sex and average age were similar in both the lupus and the control groups (table 1). The UTI prevalence was significantly higher in the lupus group: $36 \%$ $(29 / 81)$ in comparison with $9 \%(8 / 86)$. The total number of UTI episodes during the one year follow up was also much higher in lupus patients (56 in comparison with 9), as was

Table 1 Demographic data, type of lupus, prevalence and type of UTI, and type of micro-organism

\begin{tabular}{|c|c|c|}
\hline & Lupus patients & Controls \\
\hline $\begin{array}{l}\text { Number of patients } \\
\text { Age (years), mean (SD) } \\
\text { Sex (F/M) } \\
\text { Type of lupus (SLE/CL) } \\
\text { Lupus duration (years), mean (SD) } \\
\text { Prevalence of ITU, No (\%) } \\
\text { Total number with UTI } \\
\text { Number (\%) with recurrent UTI } \\
\text { Type of UTI, No (\%) } \\
\text { Asymptomatic bacteriuria } \\
\text { Uncomplicated UTI } \\
\text { Complicated UTI } \\
\text { Type of micro-organism }\end{array}$ & $\begin{array}{l}81 \\
41.4(11.9) \\
73 / 8 \\
70 / 11 \\
7.9(5.8) \\
29(36) \\
56 \\
12(15) \\
26(46) \\
27(48) \\
11(20) \\
E \text { coli } 28 \\
S \text { agalactie } 7 \\
\text { Citrobacter freundi } \\
2 \\
K \text { pneumoniae } 2 \\
P \text { mirabilis } 2 \\
P \text { vulgaris } 1 \\
E \text { faecalis } 1 \\
C \text { kasei } 1 \\
E \text { aerogenes } 1 \\
S \text { milleri } 1 \\
S \text { sanguis } 1\end{array}$ & $\begin{array}{l}8(9) \\
9 \\
0(0) \\
6(67) \\
3(33) \\
0(0) \\
E \text { coli } 6 \\
K \text { oxytoca } 1 \\
i \quad\end{array}$ \\
\hline
\end{tabular}

SLE, systemic lupus erythematosus; $\mathrm{CL}$, cutaneous lupus; UTI, urinary tract infection. the number of patients with repeated UTI. Lupus patients presented a similar percentage of uncomplicated UTIs and asymptomatic bacteriuria, whereas the UTI type that was most commonly observed in the control group was asymptomatic bacteriuria (67\%). Eleven cases of complicated UTI were recorded among lupus patients (which resulted in two admissions to hospital) and none among control subjects. Table 2 shows that no significant differences were seen between lupus and control groups in relation to UTI predisposing factors, except for urinary incontinence and low urinary frequency. These two factors were more common in lupus patients. It should be pointed out that despite the fact that the overall prevalence of urinary incontinence (including all levels of severity) was 24\%, moderate-severe incontinence was only present in seven (9\%) lupus patients. Only one of our 70 patients with SLE (1.4\%) had secondary Sjögren's syndrome (table 2). This patient had one episode of cystitis, which is $3.4 \%$ of the total number of UTIs in our lupus cohort.

\section{Micro-organisms involved in UTIs, treatment and resistance pattern}

$E$ coli was the uropathogen most frequently isolated in both groups. Table 1 shows a detailed list of the micro-organisms isolated in the urine culture. Only three controls required outpatient treatment with antibiotics, and they recovered subsequently. In the lupus group, 47 patients recovered fully from UTI, 7 relapsed, and I was re-infected. Two lupus patients were admitted to hospital to obtain parenteral antibiotic treatment for urinary sepsis. Nightly antibiotic prophylaxis was only given in 13 of the 405 visits (3.2\%) of the 81 lupus patients. Postcoital prophylaxis was given to only one lupus patient. The $E$ coli resistance pattern of lupus patients was as follows: $E$ coli was susceptible to amoxicillinampicillin $(8 / 26,31 \%)$, amoxicillin-clavulanate $(21 / 26,81 \%)$, cefalothin/cefazolin (20/26, 77\%), cefotaxime/ceftriaxone (25/ 26 , 96\%), fosfomycin (26/26, 100\%), gentamicin (25/26, $96 \%)$, pipemidic acid $(15 / 26,58 \%)$, norfloxacin (18/26, $69 \%)$, floxacin/ciprofloxacin (18/26, 69\%), trimethroprimsulfamethoxazole $(13 / 26,50 \%)$, and nitrofurantoin $(26 / 26$, $100 \%$ ). We have not included the $E$ coli resistance pattern in the controls because it was similar to that in lupus patients.

Table 2 Risk factors for UTI in lupus patients and controls

\begin{tabular}{lcc}
\hline & Lupus patients & Controls \\
\hline Number of patients & 81 & 86 \\
Sï̈gren's syndrome & $1(1)$ & $0(0)$ \\
Sexual activity & $60(74)$ & $53(62)$ \\
Chronic constipation & $32(40)$ & $24(28)$ \\
Low frequency miccional & $16(20)$ & $0(0)$ \\
Urinary incontinence & $19(23)$ & $0(0)$ \\
$\quad$ Slight & $12(15)$ & \\
Moderate & $5(6)$ & \\
Severe & $2(2)$ & $0(0)$ \\
Hypoactive bladder & $3(4)$ & $0(0)$ \\
Hyperactive bladder & $6(7)$ & $22(31)$ \\
Menopause & $15(21)$ & $16(19)$ \\
Prophylactic methods & $19(23)$ & $0(0)$ \\
Pregnancy & $0(0)$ & $0(0)$ \\
Chronic renal insufficiency & $6(7)$ & $0(0)$ \\
Renal lithiasis & $3(4)$ & $0(0)$ \\
Benign prostatic hyperplasic & $3(4)$ & $0(0)$ \\
Diabetes & $1(1)$ & \\
Urinary tract anomaly & $3(4)$ & $0(0)$ \\
Cystocele & $2(2)$ & \\
Pelvic and calyceal renal stasis & $1(1)$ & \\
Admissions because of UTI & $2 / 56(4)$ & \\
\hline Results are shown as No (\%). & & \\
\hline
\end{tabular}


Lupus activity and organ damage

For lupus activity and organ damage over the five assessments, the 70 patients with SLE presented a mean SLEDAI score of 2.3 (SD 2.6) (range 0-12) and a mean SLICC score of 0.7 (SD 1.1) (range 0-5).

\section{Laboratory test results}

Table 3 shows the laboratory test results of lupus patients with and without UTI.

\section{Treatment received}

Table 4 shows both the accumulated drug dosage, and the weekly drug dosage given to lupus patients with and without UTI throughout the study.

\section{Final results after applying generalised estimating equation (GEE) models}

The joint analysis of subjects participating in the study through an MI bivariate analysis (taking the "odds ratio (OR) cross-product ratio" as measurement) enabled us to observe a significantly different UTI distribution in both groups (lupus and control) on all five visits. Thus, controls had fewer episodes of UTI than lupus patients on all five visits $(\mathrm{OR}=0.139 ; 95 \%$ confidence interval $(\mathrm{CI}) 0.06$ to 0.33 ; $\mathrm{p}<0.001)$. This fact was confirmed by the use of the MII multivariate analysis $(\mathrm{OR}=0.22 ; 95 \%$ CI 0.11 to 0.45 ; $\mathrm{p}=0.001)$. The study of the lupus patients' epidemiological variables related to the onset of UTI through this analysis showed that the only variables associated with the possibility of having UTI were age $(p=0.002)$, previous cases of UTI $(\mathrm{p}=0.0001)$, and previous admissions to hospital due to UTI $(\mathrm{p}=0.002)$. These results were confirmed by the MII multivariate analysis (table 5 ). The rest of the variables (sexual activity $\mathrm{p}=0.81$; use of barrier methods $\mathrm{p}=0.30$; menopause $\mathrm{p}=0.39$; constipation $\mathrm{p}=0.14$; genitourinary alterations $\mathrm{p}=0.94$; Sjögrens syndrome $\mathrm{p}=0.36$ ), which were analysed jointly through the M0 analysis, did not seem to be significantly related to the onset of UTI. For the autoantibodies analysed (ANA, nDNA, SSA, SSB, RPO, Sm, aCL, and LA), only ANA levels $>1 / 80 \mathrm{IU} / \mathrm{ml}$ were significantly related to the onset of UTI ( $p=0.03$ ), which was later confirmed by the MII multivariate analysis (table 5). Likewise, when using the MI bivariate model to analyse the probable relation between the onset of UTI, leucopenia $<3 \times 10^{9} / \mathrm{l}$, thrombocytopenia $<100 \times 10^{9} / 1$, and hypocomplementaemia (C3 $<79 \mathrm{IU} / \mathrm{ml}$ and $\mathrm{C} 4<16 \mathrm{IU} / \mathrm{ml})$, only leucopenia $(\mathrm{p}=0.08)$ and C3 levels $<79 \mathrm{IU} / \mathrm{ml}$ seemed to be associated with UTI $(p=0.08)$. When the MII bivariate model was applied, it was only thrombopenia that showed a significant relation

Table 3 Results of laboratory tests from lupus patients with and without UTI

\begin{tabular}{lcc}
\hline & Lupus with UTI & Lupus without UTI \\
\hline Leucocytes $<3 \times 10^{9} \mid$ & $10 / 25(40)$ & $15 / 25(60)$ \\
Platelets $<100 \times 10^{9} \mid$ & $5 / 26(19)$ & $21 / 26(81)$ \\
C3 $<790 \mathrm{mg} / \mathrm{l}$ & $42 / 364(12)$ & $322 / 364(88)$ \\
$\mathrm{C} 4<160 \mathrm{mg} / \mathrm{l}$ & $35 / 304(12)$ & $269 / 304(88)$ \\
$\mathrm{nDNA}>100 \mathrm{IU} / \mathrm{ml}$ & $14 / 48(29)$ & $34 / 48(71)$ \\
$\mathrm{ANA}>1 / 80 \mathrm{IU} / \mathrm{ml}$ & $17 / 29(59)$ & $24 / 54(44)$ \\
$\mathrm{SS}-\mathrm{A} / \mathrm{Ro}>8 \mathrm{IU} / \mathrm{ml}$ & $23 / 29(79)$ & $37 / 50(74)$ \\
$\mathrm{SS}-\mathrm{B} / \mathrm{La}>8 \mathrm{IU} / \mathrm{ml}$ & $23 / 29(79)$ & $35 / 50(70)$ \\
$\mathrm{Sm}>15 \mathrm{IU} / \mathrm{ml}$ & $18 / 29(62)$ & $30 / 51(59)$ \\
$\mathrm{RPO}>20 \mathrm{IU} / \mathrm{ml}$ & $5 / 29(17)$ & $8 / 52(15)$ \\
$\mathrm{LA}(+)$ & $2 / 29(7)$ & $5 / 52(10)$ \\
$\mathrm{aCL}(\mathrm{IgM} \& \mathrm{IgG})>15-20 \mathrm{IU}$ & $1 / 29(3)$ & $4 / 52(8)$ \\
\hline
\end{tabular}

Results are shown as No (\%)

$\mathrm{LA}$, lupus anticoagulant; $\mathrm{aCL}$, anticardiolipin antibodies; $\lg M$, immunoglobulin $M$; lgG, immunoglobulin $G$. $(\mathrm{p}=0.02)$; we also found that leucopenia and UTI tended to be associated $(\mathrm{p}=0.093)$ (table 5$)$.

For the association between the onset of UTI and drug administration, the MI bivariate model only showed a significant relation with the weekly administration of methotrexate $(p=0.03)$, which was not totally confirmed as MII only showed a trend (table 5). Finally, no significant relation was found between the onset of UTI, and disease activity (according to the SLEDAI) $(p=0.32)$ and organ damage (according to the SLICC/ACR) $(p=0.36)$.

\section{DISCUSSION}

In previous studies, ${ }^{17}{ }^{18}$ as well as in the present research, lupus itself has been considered as an infection predisposing factor, regardless of the rest of the variables. The average age of our lupus patients was 41.4 (SD 11.9) years and was significantly associated with the onset of UTI on all five visits. This age was within the range in which UTIs and lupus have a greater occurrence. ${ }^{29}{ }^{30}$ Previous episodes of multiple urinary infection constitute another UTI predisposing factor, ${ }^{29}$ a variable that was also considered a risk factor in our study.

On the other hand, we found that sexual activity and barrier methods were not related to the onset of UTI in lupus patients. From our perspective, this may be due to the fact that sexual relations on their own cause a minimal modification of the vaginal flora, ${ }^{31}$ an essential mechanism in the pathogenesis of UTI which is directly related to the use, $^{32}$ and the frequency of use, ${ }^{33}$ of condoms. We must acknowledge that we did not measure this variable in this manner. Thus, we did not determine the number of times that patients had made use of it before a UTI episode.

As for constipation, this did not seem to constitute a UTI risk factor in the subjects of our study or in adults within the same age range. ${ }^{34}$

Anatomical and functional abnormalities in the urinary tract are known to be risk factors for the onset of complicated UTIs. ${ }^{35}$ In our cohort of lupus patients, a very reduced number of cases presented these abnormalities, which is why it was necessary to group them in order to adapt to the model. Even so, they did not appear to influence the onset of UTI. Moreover, stress incontinence did not seem to have any influence on the onset of UTI, as only two out of the 19 women had severe incontinence, and incontinence is related to the onset of UTI when it is severe. ${ }^{36}$ We found no association between UTI and low urinary frequency, a result that differs from those described by other authors, according to whom a reduction in the number of UTIs observed in premenopausal women was due to the adequate consumption of water and an appropriate number of daily urinary voidings. $^{37}$

We did not find any statistically significant associations between the disease length and the onset of UTI. This result coincides with the results of other authors, ${ }^{6-11}$ who found that lupus infections can appear at any time of the disease development without a predominance during the first years, as has been sometimes suggested. ${ }^{38} 39$

To date, no research has studied the incidence of UTI in patients with lupus and Sjögren's syndrome. None the less, there exists research devoted to patients with rheumatoid arthritis (RA) which concludes that whenever RA and Sjögren's syndrome are associated, the incidence of UTI is more frequent in those patients. ${ }^{40}$ In our research, we could not find this specific association, which may be because only a small number of lupus patients also had Sjögren's syndrome at the same time.

As for the clinical type of lupus, most studies of infections included patients with SLE, with the exclusion of patients with CL. ${ }^{5-6} 9-1141-46$ Our study, which included 70 patients with 
Table 4 Treatment of lupus patients with and without UTI

\begin{tabular}{|c|c|c|c|c|c|c|}
\hline & $\begin{array}{l}\text { Mean (SD) accumulated } \\
\text { doses }(\mathrm{mg})\end{array}$ & $\begin{array}{l}\text { Lupus with UTI } \\
\text { No (\%) }\end{array}$ & $\begin{array}{l}\text { Lupus without UTI } \\
\text { No (\%) }\end{array}$ & $\begin{array}{l}\text { Mean (SD) weekly } \\
\text { doses (mg) }\end{array}$ & $\begin{array}{l}\text { Lupus with UTI } \\
\text { No (\%) }\end{array}$ & $\begin{array}{l}\text { Lupus without UTI } \\
\text { No (\%) }\end{array}$ \\
\hline PDN & $164114(32045)$ & $26 / 189(14)$ & $163 / 189$ (86) & $364.7(83.1)$ & $39 / 216(18)$ & $177 / 216(82)$ \\
\hline $\mathrm{CLQ}$ & 449735 (150056) & $35 / 203$ (17) & $168 / 203$ (83) & $364.7(83.1)$ & $1 / 22(5)$ & $21 / 22(95)$ \\
\hline HCLQ & 129001 (46887) & $32 / 211$ (15) & $174 / 211$ (82) & $24587.2(2000)$ & $37 / 200$ (19) & $163 / 200(82)$ \\
\hline CPM & 7744 (2095) & $14 / 48(29)$ & $44 / 48$ (92) & 118.7 (10.7) & 0 & $4 / 4(100)$ \\
\hline AZA & 115326 (17479) & $11 / 60(18)$ & $49 / 60$ (82) & 123.3 (20.9) & $3 / 13(23)$ & $10 / 13(77)$ \\
\hline MTX & 297498 (3655) & $11 / 39(28)$ & $28 / 39(72)$ & $2.9(0.9)$ & $8 / 42$ (19) & $34 / 42(81)$ \\
\hline CSA & 74836 (7231) & $2 / 9(22)$ & $7 / 9(78)$ & $209.9(29.8)$ & $2 / 9(22)$ & $7 / 9(78)$ \\
\hline MMF & 170154 (22795) & $3 / 15(20)$ & $12 / 15(80)$ & $2768.6(466.7)$ & 0 & $12 / 12(100)$ \\
\hline DNZ & $29828(4400)$ & $5 / 15(33)$ & $10 / 15(67)$ & $113.8(15.8)$ & $5 / 10(50)$ & $5 / 10(50)$ \\
\hline
\end{tabular}

PDN, prednisone; CLQ, chloroquine; $\mathrm{HCLQ}$, hydroxychloroquine, CPM, cyclophosphamide; AZA, azathioprine; MTX, methotrexate; CSA, cyclosporin A; MMF, micophenolate mofetil; DNZ, danazol.

SLE $(86 \%)$ and 11 with CL (14\%), showed that the onset of UTI during the course of the study was fully independent of the clinical type of lupus.

In the analysis of autoantibodies and complement levels, only the ANA were significantly related to UTI, but not the nDNA. This finding was comparable to that obtained by Ter Borg et al in $1991^{47}$ and by other authors, ${ }^{17}$ who did not find any relation between nDNA levels and the onset of disease. As already observed by other authors, ${ }^{48}$ the association between UTIs and ANA may be due to the fact that the disease is still active in these patients and that they do not have chronic renal insufficiency, both of which are causes of the disappearance of ANA.

As for the number of leucocytes, we found some relation to the onset of UTI when they were lower than $3 \times 10^{9} /$, which had already been described..$^{32}$ This finding can be explained through the capacity of leucocytes to limit the uropathogen invasion to tissues, clearing them from urine and intervening in their dispersion control. ${ }^{32}$ Besides, the probability of patients with lupus and thrombocytopenia $<100 \times 10^{9} / 1(26 /$ $405 ; 6 \%$ ) having UTI on all five visits was 4.33 , which seems to be merely casual.

As for drugs administration, no association was found between the onset of UTI and accumulated and daily administration of corticosteroids in our lupus patients. This result is due to the fact that most our patients needed a $4.75 \mathrm{mg}$ daily dosage of prednisone, which is lower than the risk dosage for infection recorded by most authors. ${ }^{17-46}$ For the cytostatic drugs, we found a relation between the weekly dosage of methotrexate and the onset of UTI. In 1994, in a prospective study of patients with RA, Van der Veen et al analysed the probable influence of methotrexate on the onset of infection, with more infections being found in the group that had been given this drug. ${ }^{49}$ Recently, septic arthritis due to $L$ monocytogenes was recorded in a patient with SLE who was receiving low dose methotrexate treatment. ${ }^{50}$

We found no relationship between UTI and lupus activity. This may be explained by the fact that most patients had a SLEDAI score of under 4 , which is lower than that recorded in some studies as a risk indicator for SLE infection. ${ }^{13}$ It should also be pointed out that other authors, besides us, have found no association between disease activity and the onset of infection in patients with SLE. ${ }^{6-46}$

The uropathogen most frequently isolated was $E$ coli, $(28 / 47 ; 60 \%)$, a result that is similar to that described previously. ${ }^{9-10}{ }^{12-14}$ It should be borne in mind, however, that UTIs in patients with SLE do not always have a good prognosis and are likely to develop into a severe episode requiring admission to a hospital intensive care unit. ${ }^{51}$ As for the study of $E$ coli antibiotic sensitivity, the trimethoprimsulfamethoxazole resistance percentage was around 50\%, which was also related to resistance to ampicillin (69\%) and to first generation cefalosporins $(23 \%)$. In Spain there are very few data on $E$ coli antibiotic resistance patterns, one source of which is the multicentre study including Canada and 16 European countries; in this research, a TMP-SMX

Table 5 Final results of GEE model

\begin{tabular}{|c|c|c|c|c|c|c|c|c|c|}
\hline & \multirow[b]{2}{*}{ RF } & \multicolumn{4}{|c|}{ Model I (MI) } & \multicolumn{4}{|c|}{ Model II (MII) } \\
\hline & & $\overline{\mathrm{OR}}$ & $\mathrm{Cl}$ & $\operatorname{LR} \chi^{2}$ & $p$ & $\overline{\mathrm{OR}}$ & $\mathrm{Cl}$ & $\operatorname{LR} \chi^{2}$ & p \\
\hline Age & & 1.1 & 1 to 1.1 & $54.2(20)$ & 0.01 & 1.1 & 1 to 1.1 & $44.4(11)$ & 0.002 \\
\hline Sex (female) & & 0.4 & 0.1 to 2.2 & $54.2(20)$ & 0.31 & 0.3 & 0.1 to 1.7 & 44.4 (11) & 0.174 \\
\hline Previous UTI & Yes & 3.5 & 1.5 to 8.5 & $54.2(20)$ & 0.01 & 4.5 & 2 to 10 & 44.4 (11) & 0.000 \\
\hline Constipation & Yes & 1.3 & 0.6 to 2.9 & $54.2(20)$ & 0.52 & 1.3 & 0.6 to 2.8 & 44.4 (11) & 0.590 \\
\hline $\begin{array}{l}\text { Urinary anatomical or functional } \\
\text { malformation }\end{array}$ & Yes & 0.3 & 0.1 to 1.3 & $54.2(20)$ & 0.12 & 0.4 & 0.1 to 1.4 & $44.4(11)$ & 0.158 \\
\hline Admissions because of UTI & Yes & 31.4 & 3.4 to 293.6 & $54.2(20)$ & 0.01 & 15.9 & 2.8 to 91.1 & $44.4(11)$ & 0.002 \\
\hline $\mathrm{ANA}>1 / 80 \mathrm{IU} / \mathrm{ml}$ & Yes & 2.9 & 1.1 to 7.4 & $54.2(20)$ & 0.03 & 2.8 & 1.2 to 6.8 & 44.4 (11) & 0.022 \\
\hline nDNA > $100 \mathrm{lU} / \mathrm{ml}$ & Yes & 1.4 & 0.4 to 4.2 & $54.2(20)$ & 0.60 & - & - & - & - \\
\hline $\mathrm{C} 3<79 \mathrm{IU} / \mathrm{ml}$ & Yes & 2.9 & 0.9 to 9.2 & $54.2(20)$ & 0.08 & 2.1 & 0.8 to 5.6 & 44.4 (11) & 0.160 \\
\hline $\mathrm{C} 4<16 \mathrm{IU} / \mathrm{ml}$ & Yes & 0.7 & 0.3 to 2.1 & $54.2(20)$ & 0.55 & - & - & - & - \\
\hline Leucocytes $<3 \times 10^{9} / \mathrm{I}$ & Yes & 3.1 & 0.9 to 10.9 & $54.2(20)$ & 0.08 & 2.7 & 0.9 to 8.7 & $44.4(11)$ & 0.093 \\
\hline Platelets $<100 \times 10^{9} /$ I & Yes & 2.9 & 0.7 to 11.8 & $54.2(20)$ & 0.12 & 4.3 & 1.3 to 14.8 & 44.4 (11) & 0.02 \\
\hline CLQ weekly & Yes & 0.9 & 0.9 to 1 & $54.2(20)$ & 0.35 & - & - & - & - \\
\hline HCLQ weekly & Yes & 0.9 & 0.9 to 1 & $54.2(20)$ & 0.95 & - & - & - & - \\
\hline PDN weekly & Yes & 0.9 & 0.9 to 1 & $54.2(20)$ & 0.30 & - & - & - & - \\
\hline AZA weekly & Yes & 1 & 0.9 to 1 & $54.2(20)$ & 0.14 & - & - & - & - \\
\hline MTX weekly & Yes & 1.1 & 0.9 to 1.3 & $54.2(20)$ & 0.03 & 1.1 & 0.9 to 1.3 & 44.4 (11) & 0.063 \\
\hline CSA weekly & Yes & 0.9 & 0.9 to 1 & $54.2(20)$ & 0.52 & - & - & - & - \\
\hline DNZ weekly & Yes & 1.0 & 0.99 to 1.00 & $54.19(20)$ & 0.15 & - & - & - & - \\
\hline
\end{tabular}

$\mathrm{RF}$, risk factor; $\mathrm{OR}$, odds ratio; $\mathrm{Cl}$, confidence interval; $\mathrm{PDN}$, prednisone; $\mathrm{CLQ}$, chloroquine; $\mathrm{HCLQ}$, hydroxychloroquine; $\mathrm{AZA}$, azathioprine; $\mathrm{MTX}$, methotrexate; CSA, cyclosporin A; DNZ, danazol. 
resistance percentage of around $35 \%$ was detected in Barcelona, Spain..$^{52}$ On the other hand, these authors found that the $E$ coli resistance phenotype to TMP-SMX was usually associated with other antibiotic resistance, mainly to ampicillin and cefalothin, ${ }^{52}$ as is the case in our study. As for quinolones, the resistance percentage detected was around $30 \%$, a result comparable to that obtained in previous studies..$^{53}$ The $E$ coli resistance to nitrofurantoin and to fosfomycin detected in Europe was very low, ${ }^{52}$ below or equal to $2 \%$. This result is similar to the present study. Therefore, on the basis of the recommendations by the Infectious Diseases Society of America (IDSA), ${ }^{54}$ nitrofurantoin or fosfomycin would be the empirical treatment preferred for acute cystitis in our lupus patients. With regard to nitrofurantoin, it would be reasonable to be cautious when using it for the treatment of cystitis as it is a lupus-inducing drug, despite the fact that it has not been related to the idiopathic SLE activity. ${ }^{55}$ In our study, the $E$ coli resistance percentage to third generation cefalosporin and to gentamicin was $3.8 \%$. Thus, taking into account the IDSA recommendations, ${ }^{54}$ these two antibiotic families would be the first choice for our patients with lupus and pyelonephritis.

In short, lupus is a disease which, itself, predisposes patients to urinary infections. Patients with UTI who have had previous UTI episodes more frequently have leucopenia, thrombopenia, and ANA >1/80 IU/ml (regardless of nDNA levels, organ damage, and disease activity and development). UTIs are usually lower tract infections, acquired through the community, and appear repeatedly. In most cases, outpatient treatment is given and $E$ coli is the most common uropathogen. On the other hand, the $E$ coli antibiotic spectrum was similar to that described in previous studies with healthy subjects. Therefore, we suggest an empirical treatment of cystitis for our lupus patients, based on nitrofurantoin, or fosfomycin, as first choice; and, in the case of pyelonephritis, third generation cefalosporin and/or gentamicin.

\section{ACKNOWLEDGEMENTS}

The authors would like to put on record their thanks to the lupus patients belonging to the cohort 'Virgen de las Nieves', Granada, Spain, for their interest in our research, and, especially to those who participated in the present study.

\section{Authors' affiliations \\ C Hidalgo-Tenorio, J Jiménez-Alonso, J de Dios Luna, M Tallada, A Martínez-Brocal, J Mario Sabio, "Virgen de las Nieves Lupus Research Group", Systemic Autoimmune Diseases Unit, Service of Internal Medicine, "Virgen de las Nieves" University Hospital, Granada, Spain}

Other members of the "Virgen de las Nieves Lupus Research Group" are Manuel López-Gómez, Juan Pasquau, Manuel de la Rosa, Eduardo Espejo, Laura Jáimez, José Manuel Osorio, Juan Diego Mediavilla, Laura León, Pedro Luis Carrillo-Alascio, Encarnación Milla, Julián Muñoz-Alonso, David Esteva, Carmen Vera, Nuria Navarrete, Pilar Macías, Manuel Guzmán-Úbeda, Rafael Cáliz, Antonio GarcíaSánchez, Miguel Ángel Ferrer, Santiago Medialdea, Valentín GarcíaMellado, Jesús Tercedor, Elena García-Lora, Jorge Espelt, Dolores López-Segarra, Jesús Prieto, Teresa Muros, and Gonzalo Piédrola.

\section{REFERENCES}

1 Klippel JH. Systemic lupus erythematosus. Treatment-related complications superimposed on chronic disease. JAMA 1990;263:1812-15.

2 Abu-Shakra M, Mader R, Langevitz P, Friger M, Codish S, Neumann L, et al. Quality of life in systemic lupus erythematosus: a controlled study. J Rheumatol 1999:26:306-9.

3 Le Moing V, Leport C. Infections and Lupus. Rev Prat 1998;48:637-42.

4 Cervera R, Khamashta MA, Font J, Sebastiani GD, Gil A, Lavilla P, et al. Morbidity and mortality in systemic lupus erythematosus during a 5 -year period. A multicenter prospective study of 1,000 patients. European Working Party on Systemic Lupus Erythematosus. Medicine (Baltimore) 1999;78:167-75.
5 Rojas-Serrano J, Cardiel MH. Lupus patients in an emergency unit. Causes of consultation, hospitalization and outcome. A cohort study. Lupus 2000:9:601-6.

6 Nöel V, Lortholary O, Casassus P, Cohen P, Genéreau T, André MH, et al. Risk factors and prognostic influence of infection in a single cohort of 87 adults with systemic lupus erythematosus. Ann Rheum Dis 2001;60:1141-4.

7 Petri M, Genovese M. Incidence of and risk factors for hospitalizations in systemic lupus erythematosus: a prospective study of Hopkins lupus cohort. J Rheumatol 1992;19:1559-65.

8 Staples PJ, Gerding DN, Decker JL, Gordon RS. Incidence of infection in systemic lupus erythematosus. Arthritis Rheum 1974;17:1-11.

9 De Luis A, Pigrau C, Pahissa A, Fernández F, Martínez-Vazquez JM. Infections in 96 cases of systemic lupus erythematosus. Med Clin. (Barc). 1990;94:607-10.

10 Gómez J, Palazón D, Ortega G, Lucas E, Bru M, Campillo M, et al. Infections and systemic lupus erythematosus. Analysis of risk factors and prognosis. A prospective study (1979-1988). Rev Clin Esp 1991;188:72-5.

11 Uthman I, Soucy JP, Nicolet V, Senecal JL. Autosplenectomy in systemic lupus erythematosus. J Rheumatol 1996;23:1806-10.

12 Janwityanuchit S, Totemchokchyakarn K, Krachangwongchai K, Vatanasuk M. Infection in systemic lupus erythematosus. J Med Assoc Thai 1993;76:542-8.

13 Petri $\mathbf{M}$. Infection in systemic lupus erythematosus. Rheum Dis Clin North Am 1998:24:423-56.

14 Duffy WKN, Duffy CM, Gladman DD. Infection and disease activity in systemic lupus erythematosus: a review of hospitalized patients. J Rheumatol $1991 ; 18: 1180-4$.

15 Formiga Pérez F, Moga Sampere I, Canet González R, Pac Feraz M, Mitjavila Villero F, Fernández Nogues F. Infection and systemic lupus erythematosus: analysis of a series of 145 patients. Rev Clin Esp 1993;193:105-9.

16 Juega J, Pedreira JD, Adega M, Valdes F, Echaniz A. Infection in systemic lupus erythematosus. Rev Clin Esp 1989;184:245-6

17 Nived O, Sturfelt G, Wollheim F. Systemic lupus erythematosus and infection: a controlled and prospective study including an epidemiological group. $Q J$ Med 1985;55:217-87.

18 Hochberg MC. Updating the American College of Rheumatology revised criteria for the classification of systemic lupus erythematosus. Arthritis Rheum 1997:40:1725

19 Hooton TM, Scholes D, Stapleton AE, Roberts PL, Winter C, Gupta K, et al. Prospective study of asymptomatic bacteriuria in sexually active young women. N Engl J Med 2000;343:992-7.

20 Locke GR, Pemberton JH, Philips SF. American Gastroenterological Association medical position statement: guidelines on constipation. Gastroenterology 2000;1 19:1761-6.

21 Kunin CM. Urinary tract infections in females. Clin Infect Dis 1994;18:1-12.

22 Recommended terminology of urinary-tract infection. A report by the members of the Medical Research Council Bacteriuria Committee. Br Med J 1979;2:717-19.

23 Bloom DA, Foster WD, Mcleod DG, Mittemeyer BT, Stuzman RE. Costeffective uroflowmetry in men. J Urol 1985;133:421-4.

24 Chancellor MB, Rivas DA, Mulholland SG, Drake WM. The invention of the modern uroflowmeter by Willard M. Drake, Jr at Jefferson Medical College. Urology 1998;51:671-5.

25 Dupont MC, Albo M, Raz S. Diagnosis of stress urinary incontinence. Urol Clin N Am 1996:23:407-15.

26 Bomardier C, Gladman DD, Urowitz MB, Caron D, Chang CH, the Committee on Prognosis Studies in SLE. Derivation of the SLEDAI. A disease activity index for lupus patients. Arthritis Rheum 1992;35:630-40.

27 Gladman DD, Urowitz MB, Goldsmith CH, Fortin P, Ginzler E. The reliability of the Systemic Lupus International Collaborating Clinics/American College of Rheumatology damage index in patients with systemic lupus erythematosus. Arthritis Rheum 1997;40:809-13.

28 National Commite for Clinical Laboratory Standards. Performance standards for antimicrobial disk susceptibility test. 7th ed. Wayne, PA: NCCLS, 2000;20:document M2-A7.

29 Hooton TM. Patogenesis of urinary tract infections: an update. J Antimicrob Chemother 2000:46:1-7.

$30 \operatorname{Lim}$ E, Koh WH, Loh SF, Lam MS, Howe HS. Non-typhoidal Salmonellosis in patients with systemic lupus erythematosus. A study of fifty patients and review of the literature. Lupus 2001;10:87-92.

31 Hooton TM, Roberts PL, Stamm WE. Effects of recent sexual activity and use of a diaphragm on the vaginal microflora. Clin Infect Dis 1994;19:274-8.

32 Sobel JD. Pathogenesis of urinary tract infection. Infect Dis Clin North Am 1997; 11:533-49.

33 Hooton TM, Scholes D, Huches JP, Winter C, Roberts PL, Stapelton AE, et al. A prospective study of risk factors for symptomatic urinary tract infection in young women. N Engl J Med 1996;335:468-74.

34 Wagenlehner FM, Naber KG. Uncomplicated urinary tract infections in women. Curr Opin Urol 2001;11:49-53.

35 Van Haarst EP, Van Andel G, Heldeweg EA, Schlatmann TJ, Van Der Horst HJ. Evaluation of the diagnostic workup in young women referred for recurrent lower urinary tract infections. Urology 2001;57:1068-72.

36 Bjornsdottir LT, Geirsson RT, Jonsson PV. Urinary incontinence and urinary tract infections in octogenarian women. Acta Obstet Gynecol Scand 1998;77:105-9.

37 Eckford SD, Keane DP, Lamond E, Jackson SR, Abrams P. Hydration monitoring in the prevention of recurrent idiopathic urinary tract infections in pre-menopausal women. Br J Urol 1995:76:90-3.

38 Urowitz MB, Gladman DD. Eving spectrum of mortality and morbidity in SLE. Lupus 1999;8:253-5 
39 Ward MM, Pyun E, Studenski S. Causes of death in systemic lupus erythematosus. Arthritis Rheum 1995;38:1492-9.

40 Tishler M, Caspi D, Almog Y, Segal R, Yaron M. Increased incidence of urinary tract infection in patients with rheumatoid arthritis and secondary Siögren's syndrome. Ann Rheum Dis 1992;51:604-6.

41 Jacobsen S, Petersen J, Ullman S, Junker P, Voss A, Rasmussen JM, et al. A multicentre study of 513 Danish patients with systemic lupus erythematosus. II. Disease mortality and clinical factors of prognostic value. Clin Rheumtol 1998; 17:478-84

42 Koseda-Dragan M, Hebanowski M, Galinski J, Krzywinska E, Bakowska A. Asymptomatic bacteriuria in women diagnosed with systemic lupus erythematosus. Pol Arch Med Wewn 1998;100:321-30.

43 Pryor BD, Bologna SG, Kahl LE. Risk factors for serious infections during treatment with cyclophosphamide and corticosteroids for systemic lupus erythematosus. Arthritis Rheum 1996;39:1475-82.

44 Varela Aguilar JM, Sánchez Román J, Bravo Ferrer J. Severe infection in systemic lupus erythematosus. Rev Clin Esp 1990;186:97-8.

45 Paton NI. Infections in systemic lupus erythematosus patients. Ann Acad Med Singapore 1997;26:694-700.

46 Gladman DD, Hussain F, Ibañez D, Urowitz MB. The nature and outcome of infection in systemic lupus erythematosus. Lupus 2002;11:234-9.

47 Ter Borg EJ, Horst G, Hummel E, Limburg PC, Kallenberg CG. Rises in antidouble stranded DNA antibody levels prior to exacerbations of systemic lupus erythematosus are not merely due to polyclonal B cell activation. Clin Immunol Immunopathol 1991;59:117-28.
48 Reichlin M, Harley VJ. Antinuclear antibodies: an overview. In: Wallace DJ, Hahn BH, eds. Dubois' lupus erythematosus. Philadelphia: Lea \& Feiger, 1993: 188-94.

49 Van der Veen MJ, Van Der Heide A, Kruize AA, Biilsma JW. Infection rate and use of antibiotics in patients with rheumatoid arthritis treated with methotrexate. Ann Rheum Dis 1994;53:224-8.

50 Paton NI, Cheong IK, Kong NC, Segasothy M. Risk factors for infection in Malaysian patients with systemic lupus erythematosus. QJM 1996;89:531-8.

51 Cunhan BA. Infections in nonleukopenic compromised hosts (diabetes mellitus, SLE, steroids, and asplenia) in critical care. Crit Care Clin $1998 ; 14: 263-82$.

52 Kahlmeter G. The ECO-SENS project: a prospective, multinational, multicentre epidemiological survey of the prevalence and antimicrobial susceptibility of urinary tract pathogens-interim report. J Antimicrob susceptibility of urinary tract pathogens-in
Chemother 2000;46(suppl S1):15-22.

53 Garau J, Xercavins M, Rodriguez-Carballeira M, Gomez-Vera JR, Coll I, $V$ idal $D$, et al. Emergence and dissemination of quinolone-resistant Escherichia coli in the community. Antimicrob Agents Chemother 1999;43:2736-41.

54 Warren JW, Abrutyn E, Hebel JR, Johnson JR, Schaeffer AJ, Stamm WE. Guidelines for antimicrobial treatment of uncomplicated acute bacterial cystitis and acute pyelonephritis in women. Infectious Diseases Society of America (IDSA). Clin Infect Dis 1999;29:745-58.

55 Stratton MA. Drug-induced systemic lupus erythematosus. Clin Pharm 1985;4:657-63. 